\title{
lodine intakes and status in Irish adults: is there cause for concern?
}

\author{
Breige A. McNulty ${ }^{1 *}$, Anne P. Nugent ${ }^{1}$, Janette Walton ${ }^{2}$, Albert Flynn ${ }^{2}$, Christina Tlustos ${ }^{3}$ and \\ Michael J. Gibney ${ }^{1}$ \\ ${ }^{1}$ UCD Institute of Food and Health, University College Dublin, Belfield, Dublin 4, Republic of Ireland \\ ${ }^{2}$ School of Food and Nutritional Sciences, University College Cork, Cork, Republic of Ireland \\ ${ }^{3}$ Food Safety Authority of Ireland, Abbey Court, Lower Abbey Street, Dublin 1, Republic of Ireland
}

(Submitted 22 July 2016 - Final revision received 24 November 2016 - Accepted 28 November 2016 - First published online 20 February 2017)

\section{Abstract}

I is an important mineral for health, required for the production of key thyroid hormones, which are essential for cellular metabolism, growth and physical development. Hence, adequate I is crucial at all stages of life, but imperative during pregnancy for fetal brain development and during a child's early life for neurodevelopment. Within Ireland, limited information exists on population I intakes and status. Therefore, the purposes of the present analysis were to estimate dietary I intakes and to analyse urinary iodine (UI) status using the cross-sectional National Adult Nutrition Survey 2008-2010 and the most recent Irish Total Diet Study. Median I intakes in the total population ( $n$ 1106) were adequate with only $26 \%$ of the population being classified as below the estimated average requirement (EAR). Milk consumption was the major source of I in the diet, contributing $45 \%$ to total intake. Likewise, median UI concentrations ( $107 \mu \mathrm{g} / \mathrm{l})$ indicated 'optimal' I nutrition according to the WHO cut-off points. In our cohort, $77 \%$ of women of childbearing age (18-50 years) did not meet the EAR recommendation set for pregnant women. Although I is deemed to be sufficient in the majority of adult populations resident in Ireland, any changes to the current dairy practices could significantly impact intake and status. Continued monitoring should be of priority to ensure that all subgroups of the population are I sufficient.

Key words: Iodine: Dietary intakes: Status: Urinary iodine

I is an important mineral for health, required for the production of key thyroid hormones thyroxine (T4) and triiodothyronine (T3). These hormones are essential for cellular metabolism, growth and physical development. Hence, adequate I is crucial at all stages of life, but imperative during pregnancy for fetal brain development and during a child's early life for neurodevelopment ${ }^{(1)}$. Moreover, studies indicate that severe I deficiency in pregnancy is associated with intellectual deficits ${ }^{(2)}$, and mild I deficiency has been shown to impair cognition in children ${ }^{(3)}$.

Since the 1960s, the WHO has been at the forefront in the campaign to eliminate iodine deficiency disorders (IDD) globally $^{(4)}$. Salt iodisation has remained the main strategy for IDD control, and over the last two decades the number of I-insufficient countries has reduced from 110 in 1993 to thirty-two in 2012, predominately because of these fortification programmes ${ }^{(5)}$. Although progress has been made, it is still estimated that $30 \%$ of school-age children across the world have insufficient I intake ${ }^{(6)}$. Furthermore, because of a lack of data on population subgroups vulnerable to I deficiency such as pregnant women, the extent of I insufficiency within these subgroups is unknown. Moreover, Europe accounts for eleven out of the thirty-two countries with I deficiency, which is the largest from any one continent ${ }^{(5)}$. This may be because of the low number of national policies on I fortification of salt in Europe, with only seventeen out of forty European countries having implemented such programmes by $2007^{(4)}$.

Recent evidence has suggested that I deficiency has re-appeared in the UK where it was thought to have been eliminated. Concern has been raised by studies, which indicate that mild I deficiency exists in UK schoolgirls ${ }^{(7)}$ and pregnant women ${ }^{(8)}$. This would seem to be a potential major public health issue, because of the recent findings that poor I intake in pregnancy predicts a lower IQ in children ${ }^{(8,9)}$. It has been noted more recently that only $58 \%$ of pregnant women in Europe are covered by national or pooled subnational surveys, and of those countries twenty-one out of thirty-one have I intakes that are deficient ${ }^{(10)}$. Within Ireland, no current national-level population information exists on both dietary I intakes and urinary iodine (UI) status in adults. However, findings from a small Irish pregnancy cohort have suggested borderline I deficiency within this at-risk group, with $55 \%$ of pregnant women in summer and $23 \%$ in winter having UI levels $<50 \mu \mathrm{g} / \mathrm{l}^{(11)}$. There is no national

Abbreviations: EAR, estimated average requirement; LRNI, lower reference nutrient intake; NANS, National Adult Nutrition Survey; TUL, tolerable upper level; UI, urinary iodine.

* Corresponding author: Dr B. A. McNulty, fax +353 1716 1147, email breige.mcnulty@ucd.ie 
programme for I food fortification in operation in Ireland, with dairy products assumed to contribute most to dietary I intakes, chiefly as a result of the inclusion of I in animal feed and because of milk sterilisation practices.

The aim of the present study was to assess current dietary I intake and I status in the adult population resident in Ireland, using data from the national food consumption survey and total diet study, supported by UI as a biomarker, to ascertain whether there is a cause for concern in the adult population or any subgroups of the population.

\section{Methods \\ Study population}

Data for this analysis were derived from the National Adult Nutrition Survey (NANS), a cross-sectional food consumption survey carried out between 2008 and 2010 in the Republic of Ireland in a national sample of 1500 adults aged 18-90 years (men: $n$ 760; women: $n$ 740). Ethics approval was obtained from University College Cork Clinical Research Ethics Committee of the Cork Teaching Hospitals and the Human Ethics Research Committee of University College Dublin (ECM 3 (p) 4 September 2008). Written consent was obtained from all participants in accordance with the Declaration of Helsinki. A detailed description of the sampling procedures and the survey methodologies has been previously published ${ }^{(12)}$. In brief, the sample was representative of the Irish adult population with respect to age, sex, social class and urban/rural location compared with the 2006 Irish census ${ }^{(13)}$; the sample excluded pregnant and lactating women. The overall response rate of the survey was $60 \%$. In addition to food and beverage intake data, anthropometric, socio-demographic, health and lifestyle, and physical activity data were also collected along with blood and urine samples for nutritional biochemistry analyses. For the purpose of this study, only participants who provided dietary intake data in addition to having biochemical data on I status were included ( $n$ 1106).

\section{Dietary assessment and updation of the iodine composition of foods}

Food and beverage intake data were collected using a 4-consecutive-day, semi-weighed food diary (semi-weighed referring to foods weighed wherever possible), which included at least 1 weekend day. Participants were asked to weigh and record the type and amount of all food, beverages and supplements consumed, and where applicable record recipes, cooking method, brand and details of leftovers. Initial food intake data were analysed using the food composition database WISP $^{\odot}$ version 3.0 (Tinuviel Software), which uses data from McCance and Widdowson's 'The Composition of Foods' sixth and fifth editions plus all nine supplemental volumes to generate nutrient intake ${ }^{(14-24)}$. Adjustments were made to the food composition database to take account of recipes, nutritional supplements, commonly consumed generic Irish foods and new foods on the market. The database generated from the food and beverage intake data comprised 133050 rows of data. Each row of data described each food and drink item along with its nutritional content consumed by all NANS participants at every eating occasion throughout the $4 \mathrm{~d}$. A total of 2552 food codes were consumed during the survey, each food code was allocated to one of twenty-four food groups.

The I composition of foods within the Irish food composition database was deemed to be uncertain, as the majority of I data were derived from the McCance and Widdowson composition of foods. The latter data set, which is based on food available in the UK, is unlikely to fully represent I occurrence in Ireland, as I content of food varies greatly depending on the soil where the food has been grown. In addition, the database has not recently been systemically updated for I content, and therefore was unlikely to provide a reliable basis for the assessment of I intake. Therefore, work was carried out to provide accurate estimates of the I composition of foods consumed within NANS. First, an SPSS database was created containing all NANS foods consumed, including recipes. Each food item in this database was allocated a unique code that linked to the original NANS database. Second, this database was examined on a food code-by-food code basis, and each food code was assigned an I concentration $(\mu \mathrm{g} / 100 \mathrm{~g})$ on the basis of analytical data (88\%) and other published data sources (12\%).

Information to update the I composition was obtained from a number of sources; however, the majority of data came from the Irish Total Diet Study (TDS, 88\%), which was carried out by the Food Safety Authority of Ireland (FSAI) on the basis of the analytical analysis of I concentrations of foods on the Irish market using Inductively Coupled Plasma $\mathrm{MS}^{(25)}$. The methodology used in the Irish TDS has been described in detail elsewhere ${ }^{(25)}$; however, in brief, for foodstuff analysed, a number of sub-samples (typically five) were purchased. The selection of brands was based on interrogation of the brand information in the Irish food consumption databases. Sampling of the foods was conducted by the FSAI in autumn of 2012, and a total of 141 samples (comprising 1043 sub-samples) were analysed. Where required, foods were prepared ready for consumption by the laboratory before analysis. The mean I content of these foods was then matched as appropriate and applied by a food code-by-food code basis. The second information source related to specific branded products, and was obtained from information on manufacturers' websites, from nutrition panels on food labels or by directly contacting manufacturers (9\%). When information could not be obtained from the above sources, online national nutrient databanks were used - UK Food Standards Agency McCance and Widdowson's Composition of Foods Integrated Dataset ${ }^{(26)}$, Finland's National Institute for Health and Wellbeing nutrient database ${ }^{(27)}$ and the Food Standards Australia New Zealand database 'NUTTAB' (NUTrient TABles for use in Australia) ${ }^{(28)}$ (3\%). In relation to recipes, I data for each ingredient were obtained, and the proportion of each ingredient of the recipe was calculated. I concentration data were related back to actual foods and recipes as eaten in the NANS to calculate I intakes. To assess the impact of season on I intakes, for milk (whole, semi-skimmed and skimmed varieties), an I value based on season consumed obtained from the Irish TDS data set was used. 


\section{Sampling and analysis of urinary iodine concentrations}

Participants within NANS provided a first morning void urine sample. Urine samples were collected by a fieldworker at designated centres within the survey area or in the participants homes if unable to travel. Samples were collected during all months and seasons of the survey period. A total of 20-ml urine was collected in a sterile tube, kept chilled and transported to the laboratory within $5 \mathrm{~h}$ of collection for further processing. Samples were stored at $-20^{\circ} \mathrm{C}$ until required for further analysis. Samples were processed at the biological laboratories in University College Dublin and University College Cork. UI concentration was measured by a multiplate persulphate digestion method followed by the Sandell-Kolthoff colorimetry ${ }^{(29)}$. Samples were analysed blind, and quality control was provided by repeat analysis of stored batches of pooled urine samples covering a wide range of values. Intra- and inter-assay CV were $\leq 12 \cdot 8 \%$

\section{Statistical analysis}

All statistical analyses were performed using SPSS software (IBM SPSS Statistics 20). The distributions of all dietary variables and biomarkers were positively skewed; therefore, the data were presented as medians and interquartile ranges. Baseline subject characteristics were determined using descriptive analysis. Intake was compared across sex and demographic groups by using either an independent $t$ test analysis or onefactor ANOVA with Scheffé post hoc tests. A two-factor ANOVA with Scheffé post hoc tests was used to assess the impact of sex and age on I status. Differences between the percentage contributions of food groups contributing to total dietary I were compared across sex using an independent $t$ test. The ANOVA polynomial test was conducted to identify linear trends in biomarkers across consumption categories with respect to UI.

Dietary I intake was assessed against national and international reference values, including the UK lower reference nutrient intake $(\mathrm{LRNI})^{(30)}$, the adequate intake (AI) established by the European Food Safety Authority (EFSA) ${ }^{(31)}$, the estimated average requirement (EAR) established by the US Institute of Medicine (IOM) ${ }^{(32)}$ and tolerable upper level (TUL) for adults derived by the EU Scientific Committee on Food (SCF) ${ }^{(33)}$. The prevalence of the populations not meeting these recommendations was assessed excluding participants classified as under-reporters of energy intake $(31 \%)$, identified as having a ratio of energy intake:BMR of $<1.05^{(34)}$. The WHO cut-off points were applied to classify I nutrition - median UI $<100 \mu \mathrm{g} / \mathrm{l}$ defines a population that has I deficiency ${ }^{(2)}$.

To examine the effect of season and milk consumption on I intake and status, specific categories were created as follows: season was classified into four categories (January-March; April-June; July-September; October-December). Consumers of milk were divided into tertiles on the basis of their average daily intake of whole, semi-skimmed and skimmed milk. In addition, non-consumers were also analysed; these were participants who recorded no consumption of milk during the survey. A one-factor ANOVA with Scheffé post hoc tests was used to assess I intake and urine I excretion across season and milk consumption categories described above. For all statistical analyses, continuous variables were log transformed to normalise their distribution, and $P<0.05$ was considered statistically significant.

\section{Results \\ Study population characteristics}

Of the 1500 adults recruited within NANS, $75 \%$ provided a urine sample along with dietary data ( $n$ 1121). Of these, fifteen participants had to be excluded as UI values were below the assay detection limit of $<15 \mu \mathrm{g} / \mathrm{l}$, and therefore not classified as a reliable UI concentration, leaving a total of 1106 Irish adults to be included in the present study. The participants were representative of the Irish adult population in terms of age, sex, social class and location ${ }^{(12,13)}$. In total, $71 \%$ of males and $56 \%$ of females were classified as overweight/obese, and $19 \%$ of the participants were current smokers. Furthermore, $33 \%$ of the cohort consumed at least one nutritional supplement, with more females (36\%) consuming nutritional supplements than males (29\%, $P=0.008)$ (online Supplementary Table S1).

\section{lodine intake in the total adult population}

Median intakes and inter-quartile ranges of total I split by sex and age group across demographic and lifestyle characteristics are presented in Table 1. Overall intake across all age groups was significantly higher in males $(141 \mu \mathrm{g} / \mathrm{d})$ compared with females $(104 \mu \mathrm{g} / \mathrm{d}) \quad(P<0.001)$. For females, a significant $(P<0.05)$ increase in I intake was observed across age groups with younger females (18-35 years) having the lowest intake $(95 \mu \mathrm{g} / \mathrm{d})$ and females $\geq 65$ years having the highest intake $(123 \mu \mathrm{g} / \mathrm{d})$. No significant difference was observed across male age groups. Significantly higher I intake was observed in supplement users $(142 \mu \mathrm{g} / \mathrm{d})$ compared with non-supplement users $(114 \mu \mathrm{g} / \mathrm{d})$; however, this difference appears to be driven by female supplement users, as a significant difference was only noted between female supplement users and non-supplement users (Table 1).

The percentages of Irish adults meeting dietary recommendations pertaining to the UK's LRNI $(<70 \mu \mathrm{g} / \mathrm{d})$, EFSA's AI $(150 \mu \mathrm{g} / \mathrm{d})$ in addition to the IOM EAR $(95 \mu \mathrm{g} / \mathrm{d})$, and SCF TUL $(>600 \mu \mathrm{g} / \mathrm{d})$ for adults are described in Table 2 . The results show that overall $12 \%$ of the population did not meet the LRNI, with $8 \%$ of men and $15 \%$ of women showing intakes below the LRNI. Furthermore, $26 \%$ of the population did not meet the EAR; when split by sex, this relates to $17 \%$ of males and $34 \%$ of females. The EAR for pregnant women was $160 \mu \mathrm{g} / \mathrm{d}$, and when applied to the 18-50 years age group within this population, $77 \%$ did not meet this recommendation (data not shown). Overall, less than $1 \%$ of the population exceed the TUL for I.

The percentage contributions of twenty-two food groups to mean daily I intake were assessed, and this analysis was based on average intakes; hence, mean daily intakes are reported within Table 3. In the total population, the main sources of I were 'whole milk' and 'low-fat, skimmed and fortified milks' providing $40 \%$ of I intake. When split by sex, these food groups combined provided $43 \%$ of I intakes in males and $37 \%$ in 
Table 1. Median intakes and interquartile ranges of total iodine $(\mu \mathrm{g} / \mathrm{d})$ split by sex and age group across demographic and lifestyle characteristics* (Medians and interquartile ranges (IQR))

\begin{tabular}{|c|c|c|c|c|c|c|c|}
\hline & \multicolumn{2}{|c|}{ Total population ( $n$ 1106) } & \multicolumn{2}{|c|}{ Men $(n$ 543) } & \multicolumn{2}{|c|}{ Women ( $n$ 563) } & \multirow[b]{2}{*}{$P \dagger$} \\
\hline & Median & IQR & Median & IQR & Median & IQR & \\
\hline All (18-90 years) & $121 \cdot 3$ & $82 \cdot 6,184 \cdot 6$ & $141 \cdot 0$ & $96 \cdot 8,209 \cdot 1$ & 103.5 & $72 \cdot 6,162 \cdot 7$ & $<0.001$ \\
\hline \multicolumn{8}{|l|}{ Age groups (years) } \\
\hline 18-35 & $122 \cdot 8$ & $80 \cdot 7,186 \cdot 6$ & $154 \cdot 0$ & $97.5,217.5$ & $94.9^{a}$ & $70 \cdot 7,144 \cdot 5$ & $<0.001$ \\
\hline $36-50$ & $115 \cdot 5$ & $78.8,174.4$ & $132 \cdot 1$ & $92 \cdot 8,226 \cdot 3$ & $100 \cdot 9^{a, b}$ & $68.9,156 \cdot 6$ & 0.047 \\
\hline $51-64$ & $122 \cdot 2$ & $86 \cdot 8,185 \cdot 5$ & 134.7 & $95 \cdot 7,196 \cdot 3$ & $113 \cdot 8^{\mathrm{a}, \mathrm{b}}$ & $80.5,171.0$ & 0.182 \\
\hline$\geq 65$ & $127 \cdot 9$ & $93 \cdot 2,194.2$ & $130 \cdot 2$ & $105 \cdot 3,194 \cdot 8$ & $123 \cdot 2^{\mathrm{b}}$ & $84 \cdot 8,194 \cdot 2$ & 0.461 \\
\hline \multicolumn{8}{|l|}{ Social class } \\
\hline Professional/managerial/technical & 130.5 & $86 \cdot 1,186 \cdot 3$ & $140 \cdot 2$ & $94.7,205 \cdot 9$ & $116 \cdot 9$ & $78 \cdot 4,170 \cdot 2$ & 0.018 \\
\hline Non-manual skilled & 118.7 & $78 \cdot 3,177 \cdot 8$ & $142 \cdot 7$ & $93 \cdot 9,213 \cdot 0$ & 103.5 & $70 \cdot 4,161 \cdot 4$ & 0.031 \\
\hline Manual skilled & 109.6 & $83 \cdot 6,187 \cdot 5$ & $121 \cdot 0$ & $89 \cdot 5,200 \cdot 1$ & $102 \cdot 3$ & $76 \cdot 7,169 \cdot 3$ & 0.152 \\
\hline Semi-skilled/unskilled/students & $120 \cdot 0$ & $82 \cdot 9,190 \cdot 2$ & $152 \cdot 6$ & $98 \cdot 7,221 \cdot 2$ & $91 \cdot 1$ & $66 \cdot 7,140 \cdot 9$ & 0.021 \\
\hline \multicolumn{8}{|l|}{ Location } \\
\hline Open country/small town $(<9999) \ddagger$ & $110 \cdot 6$ & $76 \cdot 3,166 \cdot 9$ & $131 \cdot 3$ & $94 \cdot 0,201 \cdot 2$ & $96 \cdot 0^{\mathrm{a}}$ & $68.3,144 \cdot 0$ & $<0.001$ \\
\hline Large town $(>10000)$ & $122 \cdot 4$ & $81.9,183.5$ & 143.0 & $98 \cdot 3,210 \cdot 8$ & $101 \cdot 7^{\mathrm{a}, \mathrm{b}}$ & $71 \cdot 3,157 \cdot 1$ & $<0.001$ \\
\hline City (Dublin/Cork) & 134.5 & $85 \cdot 7,198.0$ & $145 \cdot 0$ & $97 \cdot 3,218 \cdot 2$ & $119 \cdot 7^{\mathrm{b}}$ & $81 \cdot 8,186 \cdot 3$ & 0.035 \\
\hline \multicolumn{8}{|l|}{ BMI } \\
\hline Normal weight & 124.1 & $84 \cdot 6,181 \cdot 4$ & $157 \cdot 3$ & $105 \cdot 4,209 \cdot 2$ & $109 \cdot 5$ & $72 \cdot 4,156 \cdot 6$ & 0.035 \\
\hline Overweight & $126 \cdot 1$ & $84 \cdot 3,202 \cdot 3$ & $135 \cdot 8$ & $92 \cdot 7,216 \cdot 1$ & $116 \cdot 8$ & $76 \cdot 8,185.5$ & 0.005 \\
\hline Obese & 111.2 & $80.5,168.2$ & $127 \cdot 0$ & $90 \cdot 6,177 \cdot 9$ & $92 \cdot 1$ & $69 \cdot 9,156 \cdot 2$ & 0.129 \\
\hline \multicolumn{8}{|l|}{ Smoking status } \\
\hline Smoker & $107 \cdot 8$ & $71 \cdot 6,167 \cdot 7$ & 143.5 & $94.7,191 \cdot 3$ & 84.5 & $58 \cdot 7,125 \cdot 9$ & 0.038 \\
\hline Non-smoker & $124 \cdot 0$ & $85 \cdot 7,189 \cdot 2$ & $140 \cdot 3$ & $97 \cdot 3,213 \cdot 8$ & $113 \cdot 0$ & $76 \cdot 6,168 \cdot 3$ & $<0.001$ \\
\hline \multicolumn{8}{|l|}{ Supplement user } \\
\hline Yes & $141.5^{\mathrm{a}}$ & $95 \cdot 8,213 \cdot 7$ & 153.9 & $113 \cdot 1,238 \cdot 4$ & $128 \cdot 5^{\mathrm{a}}$ & $84 \cdot 7,195 \cdot 1$ & 0.095 \\
\hline No & $113.7^{b}$ & $79 \cdot 1,170 \cdot 2$ & $133 \cdot 1$ & $92 \cdot 2,202 \cdot 0$ & $94.5^{\mathrm{b}}$ & $67 \cdot 9,140 \cdot 8$ & $<0.001$ \\
\hline
\end{tabular}

a,b Median values with unlike superscript letters are significantly different between groups $(P<0.05)$.

* Differences across demographics were assessed by ANOVA or independent $t$ test. This refers to comparisons within a demographic/lifestyle characteristic, for one sex (such as,

for example, between age groups for women, or between supplement users and non-users for the total population).

$\dagger$ Differences between sexes were assessed by an independent $t$ test.

$\ddagger$ Refers to number of inhabitants.

Table 2. Percentage of Irish adults (18-90 years) not meeting recommended iodine intakes

\begin{tabular}{lcccc}
\hline & $\begin{array}{c}\text { \% population below } \\
\text { LRNI of } 70 \mu \mathrm{g} / \mathrm{d}^{*}\end{array}$ & $\begin{array}{c}\text { \% population below } \\
\text { EAR of } 95 \mu \mathrm{g} / \mathrm{d} t\end{array}$ & $\begin{array}{c}\text { \% population below } \\
\text { Al of } 150 \mu \mathrm{g} / \mathrm{d} \ddagger\end{array}$ & $\begin{array}{c}\text { \% population above } \\
\text { TUL of } 600 \mu \mathrm{g} / \mathrm{d} \S\end{array}$ \\
\hline Total population & & & & \\
All & 11.5 & 25.5 & 55.0 & 0.4 \\
Men & 7.7 & 17.1 & 45.4 & 0.6 \\
Women & 15.2 & 33.9 & 64.7 & 0.0 \\
\hline
\end{tabular}

LRNI, lower reference nutrient intake; EAR, estimated average requirement; Al, adequate intake; TUL, tolerable upper level.

* Department of Health ${ }^{(30)}$.

$\dagger$ Institute of Medicine ${ }^{(32)}$.

$\ddagger$ European Food Safety Authority ${ }^{(31)}$

$\S$ Scientific Committee on Food ${ }^{(33)}$.

females, respectively, with males obtaining slightly more I from the food group 'whole milk' compared with females $(P<0 \cdot 001)$. Other food groups that contributed 5-7\% towards I intake across both sexes were 'fish and fish dishes', 'beverages' (inclusive of alcoholic and non-alcoholic beverages) and 'egg and egg dishes'.

\section{lodine status in the Irish adult population}

The median concentration of UI in the total population was $107 \mu \mathrm{g} / \mathrm{l}$, with a lower median status observed in females $(101 \mu \mathrm{g} / \mathrm{l})$ compared with that of the male population $(116 \mu \mathrm{g} / \mathrm{l})$. In both sexes, I status appeared to decline across age groups; however, this was not significant (Table 4). WHO cut-off points classifying
I nutrition into different degrees of public health significance were used to characterise the findings of this study; overall, the Irish population met criteria for optimal I nutrition (i.e. median UI $100-199 \mu \mathrm{g} / \mathrm{l})$, with a median concentration of $107 \mu \mathrm{g} / \mathrm{l}^{(35)}$.

\section{Influence of milk consumption and season on iodine intake and status}

I intake and status were examined across quartiles of milk consumption (Fig. 1). A significant positive relationship was observed, whereby an increase in milk consumption related to a significant stepwise increase in both dietary intakes of I and also in UI concentrations $(P<0 \cdot 001)$. The I content of milk can vary by season because of differences in animal husbandry with animals 
Table 3. Percentage contribution of food groups to intakes of iodine split by sex

(Mean values and standard deviations)

\begin{tabular}{|c|c|c|c|c|c|}
\hline & $\begin{array}{l}\% \text { consumers } \\
\text { of food groups }\end{array}$ & All & Men & Women & $P^{*}$ \\
\hline \multicolumn{6}{|l|}{ Food groups } \\
\hline Whole milk & 60 & 20.3 & 24.4 & $16 \cdot 4$ & $<0.001$ \\
\hline $\begin{array}{l}\text { Low-fat, skimmed } \\
\text { and fortified milks }\end{array}$ & 51 & 19.6 & $18 \cdot 2$ & 20.9 & 0.072 \\
\hline Fish and fish dishes & 53 & 6.4 & 6.5 & $6 \cdot 3$ & 0.779 \\
\hline Beverages & 100 & $6 \cdot 2$ & $6 \cdot 2$ & $6 \cdot 2$ & 0.967 \\
\hline Eggs and egg dishes & 51 & 5.9 & 6.0 & $5 \cdot 8$ & 0.710 \\
\hline Breakfast cereals & 75 & $4 \cdot 3$ & 4.5 & $4 \cdot 1$ & 0.535 \\
\hline Yogurts & 44 & 4.6 & 3.7 & 5.5 & $<0.001$ \\
\hline $\begin{array}{l}\text { Meat and meat } \\
\text { products }\end{array}$ & 98 & 4.1 & 4.4 & 3.7 & 0.005 \\
\hline $\begin{array}{l}\text { Grains, rice, pasta } \\
\text { and savouries }\end{array}$ & 71 & 3.3 & 3.6 & 2.9 & 0.067 \\
\hline $\begin{array}{l}\text { Chocolate } \\
\text { Confectionery }\end{array}$ & 49 & 3.1 & 2.5 & 3.6 & $<0.001$ \\
\hline $\begin{array}{l}\text { Creams, ice-creams } \\
\text { and desserts }\end{array}$ & 47 & 3.4 & 3.0 & 3.8 & 0.032 \\
\hline $\begin{array}{c}\text { Other milk and milk- } \\
\text { based beverages }\end{array}$ & 13 & $2 \cdot 6$ & 1.7 & 3.5 & 0.001 \\
\hline Cheeses & 65 & 2.7 & $2 \cdot 7$ & $2 \cdot 7$ & 0.089 \\
\hline $\begin{array}{l}\text { Biscuits, cakes and } \\
\text { pastries }\end{array}$ & 77 & $2 \cdot 2$ & $2 \cdot 2$ & $2 \cdot 2$ & 0.860 \\
\hline $\begin{array}{l}\text { Nutritional } \\
\text { supplements }\end{array}$ & 33 & $2 \cdot 6$ & 1.9 & 3.2 & 0.046 \\
\hline $\begin{array}{l}\text { Fruits and fruit } \\
\text { dishes }\end{array}$ & 82 & 1.6 & 1.5 & 1.7 & 0.253 \\
\hline $\begin{array}{l}\text { Soups, sauces and } \\
\text { miscellaneous foods }\end{array}$ & 85 & 1.5 & 1.4 & 1.6 & 0.143 \\
\hline $\begin{array}{l}\text { Vegetables and veg } \\
\text { dishes }\end{array}$ & 97 & 1.4 & $1 \cdot 2$ & 1.6 & 0.020 \\
\hline Bread and rolls & 99 & 1.3 & 1.4 & 1.3 & 0.264 \\
\hline $\begin{array}{l}\text { Potatoes and potato } \\
\text { dishes }\end{array}$ & 93 & 1.3 & 1.3 & 1.3 & 0.758 \\
\hline $\begin{array}{l}\text { Butter, spreading } \\
\text { fats and oils }\end{array}$ & 89 & 1.2 & 1.3 & $1 \cdot 1$ & 0.121 \\
\hline $\begin{array}{l}\text { Sugars, preserves } \\
\text { and savoury snacks }\end{array}$ & 81 & 0.4 & 0.4 & 0.4 & 0.447 \\
\hline $\begin{array}{l}\text { Non-chocolate } \\
\text { confectionery }\end{array}$ & 23 & 0.1 & 0.1 & 0.1 & 0.103 \\
\hline $\begin{array}{l}\text { Nuts, seeds, herbs and } \\
\text { spices }\end{array}$ & 23 & 0.1 & 0.0 & 0.1 & 0.037 \\
\hline Total (\%) & & 100 & 100 & 100 & \\
\hline \multicolumn{6}{|l|}{ Daily I intake $(\mu \mathrm{g} / \mathrm{d})$} \\
\hline Mean & & 149 & 170 & 129 & \\
\hline SD & & 109 & 128 & 84 & \\
\hline
\end{tabular}

${ }^{*}$ Differences between sexes were assessed by an independent $t$ test.

fed on pasture rather than on concentrates resulting in winter milk having a higher I content compared with summer. Therefore, the influence on intake and status was examined and is shown in Fig. 2. As expected, because of the adjustment of I content of milk by month surveyed, significant differences were observed, with participants surveyed in winter having higher I status. A stepwise increase can be seen with the highest intakes observed in January to March $(202 \mu \mathrm{g} / \mathrm{d})$ and lowest intakes between July and September $(103 \mu \mathrm{g} / \mathrm{d} ; P=0.002)$. A similar pattern can be observed when UI are examined by season, with significantly higher concentrations being observed between January and March $(152 \mu \mathrm{g} / \mathrm{l})$ and lowest UI concentrations between July and September $(108 \mu \mathrm{g} / \mathrm{l})$, respectively. Furthermore, when UI was spilt by season, the percentage of the population defined as deficient by the WHO cut-off points was 50\% during summer (AprilSeptember) compared with $43 \%$ during winter (October-March). Stepwise regression analysis conducted to investigate the relationship of both dietary I intakes and UI concentrations with milk

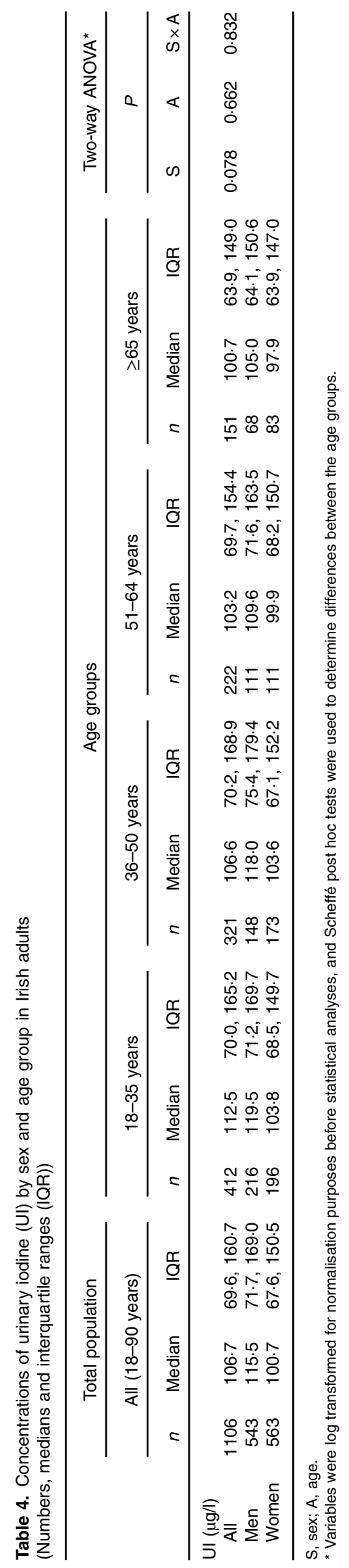




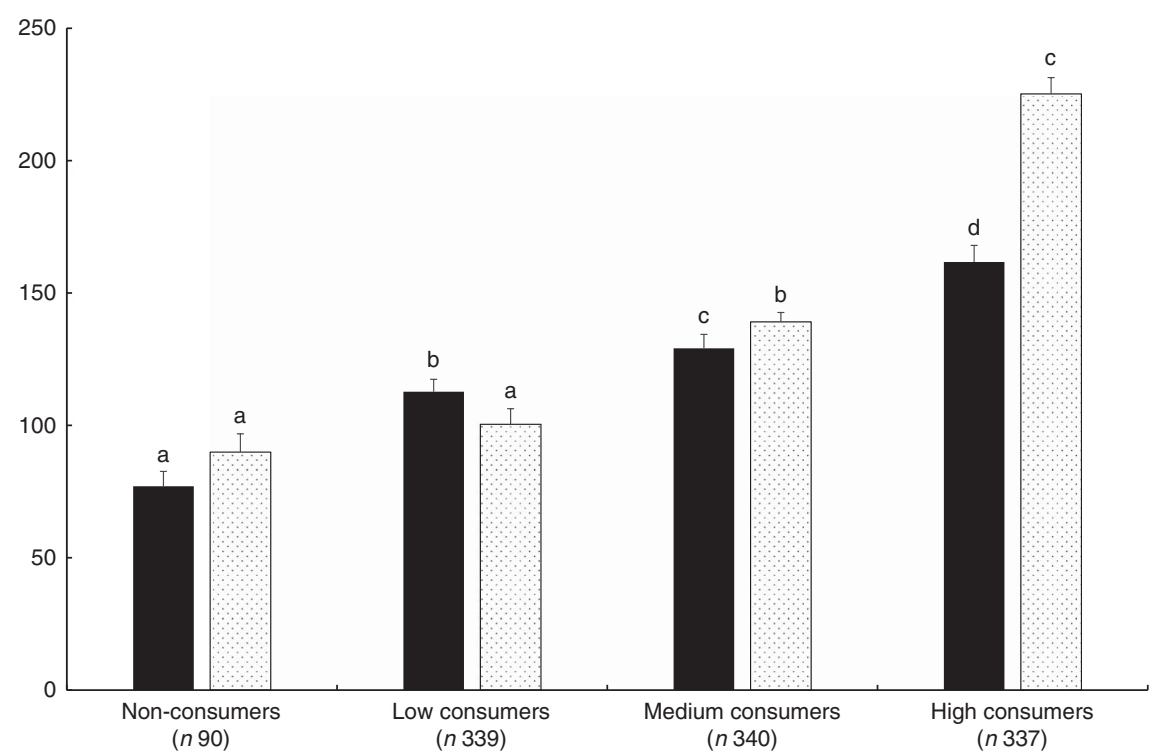

Fig. 1. The relationship between quartiles of milk consumption and dietary intakes of iodine ( ; $\mu \mathrm{g} / \mathrm{d})$ and urinary iodine ( $\mathbf{\square} ; \mu \mathrm{g} / \mathrm{l})$. Milk intakes used to calculate consumption groups refer to consumption of whole, semi-skimmed and skimmed milks; non-consumers recorded no consumption of milk $(0 \mathrm{~g} / \mathrm{d})$, low consumers $(61 \mathrm{~g} /$ d), medium consumers $(174 \mathrm{~g} / \mathrm{d})$ and high consumers $(418 \mathrm{~g} / \mathrm{d})$. In each graph, differences between consumption groups were assessed using ANOVA with Scheffé post hoc test. a,b,c,d Mean values with unlike letters were significantly different $(P<0.001)$.

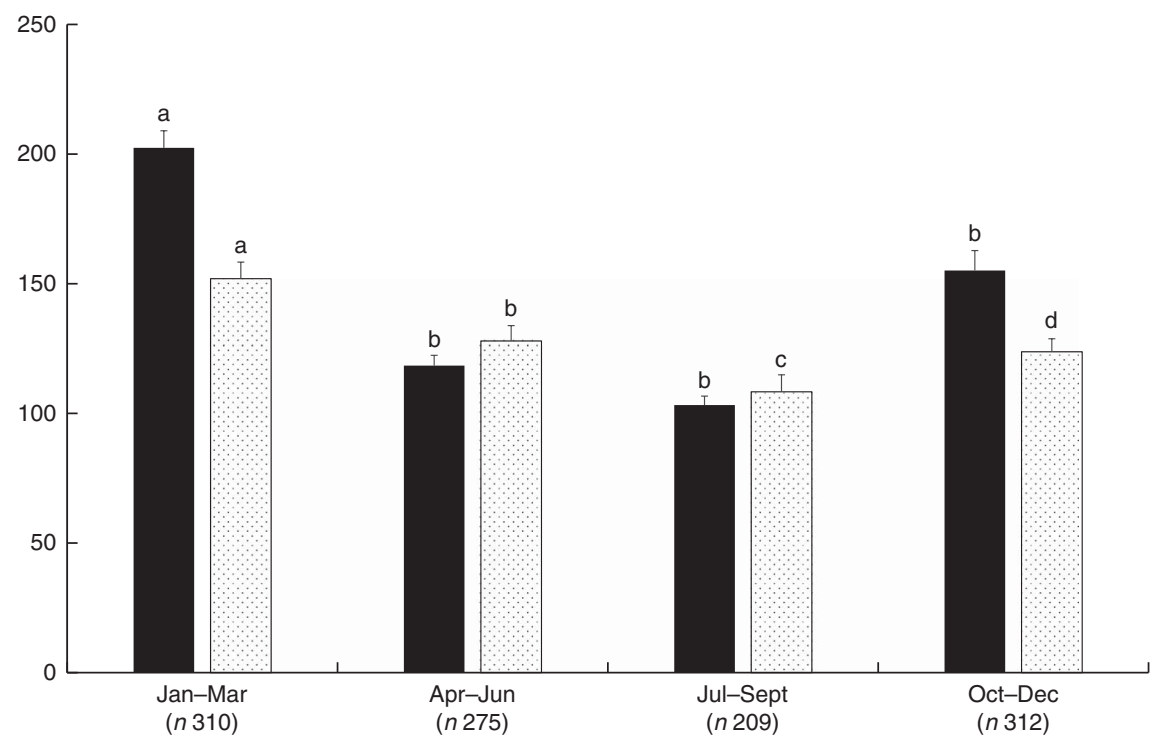

Fig. 2. The relationship between season and dietary intakes of iodine ( $; \mu \mathrm{g} / \mathrm{d})$ and urinary iodine ( $\square$; $\mu \mathrm{g} / \mathrm{l})$. Season was divided into four groups - January-March, April-June, July-September and October-December. In each graph, differences between groups was assessed using ANOVA with Scheffé post hoc test. a,b,c,d Mean values with unlike superscripts letters were significantly different $(P<0.001)$.

intake and season found a significant relationship with both $(P<0 \cdot 001 ;$ data not shown).

\section{Discussion}

The findings of the present study suggest that the majority of adults resident in Ireland are I sufficient, with $26 \%$ of the population having dietary intakes below the EAR. In addition, UI concentrations indicate optimal I nutrition in the same population. Milk consumption is the major food source of I within Ireland, and this study showed a significant relationship between milk consumption and both estimated dietary intake and UI status. These findings further suggest that I sufficiency in the adult population resident in Ireland is largely reliant on one single food source (i.e. milk). This study also highlights the influence of season on I intake and status reflecting the seasonal change of I content in milk, with the Irish population having the lowest I intake and status during the summer months. Although adults resident in Ireland can be classified as I sufficient, certain groups within the population may be at risk of marginal deficiencies. Young females were reported to have the lowest intakes and statuses of I, which may lead to concerns that 
pregnant women may not be getting AI during the critical period of fetal development.

Median intakes of I of $141 \mu \mathrm{g} / \mathrm{d}$ in males and $104 \mu \mathrm{g} / \mathrm{d}$ in females in the present study were found to be comparable with other European countries ${ }^{(36)}$. In the UK National Diet and Nutrition Survey, slightly higher I intakes were reported with males consuming $192 \mu \mathrm{g} / \mathrm{d}$ and females $143 \mu \mathrm{g} / \mathrm{d}^{(37)}$. These intake differences may explain the higher percentage of the population not meeting the LRNI within the present study ( $8 \%$ males, $15 \%$ females) compared with the UK (2\% males; $6 \%$ females ${ }^{(38)}$. In the USA, results from a total diet study indicated I intakes of $192-284 \mu \mathrm{g} / \mathrm{d}$ in men aged 25-65 years and $138-197 \mu \mathrm{g} / \mathrm{d}$ in women aged $25-65$ years $^{(39)}$; these higher intakes to some extent could be attributed to the higher availability of iodised salt within America ${ }^{(40)}$. At present, in Ireland, no practice exists in relation to mandatory or voluntary iodised salt fortification. Across many European countries, milk appears to be the major food source of I. In the UK, milk contributes $33 \%$ to intakes, in Germany $42 \%$ and in Denmark $44 \%(36,38,41)$. An equivalent contribution was observed within the present study with milk contributing to $40 \%$ of intakes. A difference in sex was noted, with males showing a slightly higher contribution from milk (43\%) compared with females ( $37 \%)$, due to overall higher milk intakes in males. Other food sources that contributed $>7 \%$ to intakes were 'fish and fish dishes', 'beverages' and 'egg and egg dishes'. Similar food group contributors to I intake were noted in the UK, although 'fish and fish dishes' and 'beer and lager' contributed slightly more to UK intakes ${ }^{(38)}$. These differences in the contribution of food sources to I may relate to differences in I content of food or indeed the slight difference in food intake patterns that exist between both countries.

The median UI concentration in the present study was $107 \mu \mathrm{g} / \mathrm{l}$ for the adult population resident in Ireland, indicating that adults are I sufficient; however, population subgroups with borderline status may exist. Previous reports from Ireland suggested the possibility of I insufficiency during pregnancy ${ }^{(11,42)}$. Recently, in the UK, I has re-emerged as a public health issue ${ }^{(43)}$. Although thought to be I sufficient for many years ${ }^{(44)}$, current evidence has suggested that I deficiency exists in subgroups of the population $^{(7,8)}$. Vanderpump et al $^{(7)}$ reported that $51 \%$ of UK schoolgirls aged 14-15 years attending secondary school in nine UK centres surveyed were deemed to have mild I deficiency, $16 \%$ moderate deficiency and $1 \%$ severe deficiency. In the present study, somewhat similar findings were observed in the overall population.

In terms of public health nutrition policy, I deficiency is of greatest importance in women of childbearing age and young children. I is a component of the thyroid hormones T4 and T3, which play a central role in brain development of the fetus in the early stages of pregnancy. Reports from both Australia and the UK indicate that poor I intake in pregnancy predicts a lower IQ in children $^{(8,9)}$. In the Avon Longitudinal Study of Parents and Children, the associations between maternal I status in the first trimester and child IQ at age 8 years and reading ability at age 9 years were assessed in 1040 women and infant pairs. After adjustment for confounders, children of I-deficient women were more likely to have scores in the lowest quartile for verbal IQ and reading accuracy and reading comprehension ${ }^{(8)}$. This longitudinal study and others highlight the importance of sufficient I during pregnancy. The EAR for pregnant women is currently $160 \mu \mathrm{g} / \mathrm{d}^{(32)}$, and when this cut-off point was applied to women of childbearing age (18-50 years) in our cohort, $77 \%$ had intakes below this recommendation. In addition, UI status within this subgroup was $104 \mu \mathrm{g} / \mathrm{l}$, which would be considered insufficient on the basis of the WHO cut-off points for pregnant women. These data suggest that a potential problem may exist within this at-risk group of young females, and these findings should be validated as targeted public health messages may be required.

Within the present study, milk consumption was found to have a positive relationship with both I intake and UI concentration. The high content of I in milk is partly due to sterilisation practices, which use iodised cleansing solutions in addition to the introduction of I-enriched salt licks to dairy cows. Since the 1960s, I deficiency has been vastly reduced because of these indirect methods, and I is thought to be sufficient in the Irish diet. Across intakes of milk, a significant stepwise increase was observed in both I intake and urine I concentrations. This relationship highlights the importance of milk as the main food source of I in Ireland. An equivalent relationship with milk consumption in a Danish population has also been reported ${ }^{(36)}$. Although the majority of Irish adults consume milk (approximately 97\%), the recent increase in milk alternatives on the Irish market should be considered. Although only $2 \cdot 4 \%$ of adults were consumers of these products in the present study, a recent study in the UK has indicated that these unfortified milk-alternative drinks are not a suitable substitute in terms of I content, and consumers of milk alternatives may be at risk of I deficiency ${ }^{(45)}$.

In Ireland, I concentration in milk varies depending on season, with higher I concentrations being recorded during winter ${ }^{(25)}$. This fluctuation within the I content of milk can be observed in UI concentrations of the population, with participants surveyed in winter having significantly higher UI concentrations $(152 \mu \mathrm{g} / \mathrm{l})$ compared with participants surveyed during summer months $(108 \mu \mathrm{g} / \mathrm{l})$. This seasonal difference can be explained by the use of salt licks and cow fodder fortified with I used during winter months. In the present study, a clear pattern across season can be observed - both I intake and UI showed a decline when approaching summer and then increased again in winter. These results highlight the fact that within the Irish population milk is the predominant food source of I, and any changes in the I content of milk may have a major impact in the adequacy levels of the population, which may have negative public health implications. EFSA has recommended a reduction of the maximum permitted levels for I in complete feed, from 5 to $2 \mathrm{mg} / \mathrm{kg}$; this recommendation was made after a risk assessment concluded that for certain groups of the population the TUL was being exceeded ${ }^{(46)}$. These calculations, however, were based on European-level data. In the present study, only $0 \cdot 1 \%$ of the population were found to exceed the TUL, which indicates that this is not a concern in Ireland, and this has also been noted within the $\mathrm{UK}^{(38)}$.

Many countries around the globe have introduced salt fortification as a means to maintain sufficient I status in their populations. Salt is one of the main vehicles used for fortification, with the WHO recommending an I concentration of 
$14-65 \mathrm{mg} / \mathrm{kg}$ of salt ${ }^{(47)}$. Within parts of Europe and across the world, fortification has been a mandatory or voluntary policy for many years, with Switzerland being the first country to introduce such a policy in $1922^{(4)}$. Switzerland as well as other countries who introduced mandatory I fortification are classified as I sufficient and have maintained this status for many years ${ }^{(4)}$. More recently, mandatory I fortification has been established in other parts of the world. In 2009, Australia and New Zealand introduced mandatory addition of iodised salt to all yeastleavened bread (excluding organic bread) ${ }^{(48)}$. Since fortification, reports have shown that in 8-10-year-old New Zealand children, median UI concentrations have nearly doubled, with an increase from 66 to $113 \mu \mathrm{g} / \mathrm{l}$. This represents a decrease in the percentage of children classified as moderately deficient from 28 to $12 \%$. Feasibility of food fortification with I would have to be carefully considered in the Irish context. In addition, a suitable food vehicle would have to be identified. However, in the first instance, continued monitoring is required, especially in at-risk groups such as pregnant women to assess whether I intakes are insufficient within this group.

The present study has many strengths. It is based on a nationally representative sample of the adult population resident in Ireland, and it combined detailed dietary data (collected to brand level), with recent analytically determined I values for foods consumed in Ireland, including seasonal values for Irish milk. Furthermore, as iodised salt is rarely consumed within Ireland, this study gives a realistic estimation of dietary I intakes. This study is somewhat unique in that it does not rely on standard food composition tables. The I content of almost $90 \%$ of all foods was derived from the Irish TDS, all of which are based on direct chemical analysis of recent food purchases, cooked or otherwise, as are the national norms. Nevertheless, it should be noted that only a limited number of food composite samples analysed for I content were available for matching with a wide range of survey food codes, which is a limitation. We also acknowledge that some variability in I values from specific branded products from manufacturers may exist because of the permitted tolerances for nutrient values, while rounding of values should also be considered ${ }^{(49)}$. In addition to detail dietary data, urine samples were also collected from the same cohort, which is a strength of the present study. However, the latter were collected as spot urine samples, which are not the preferred method to estimate I concentrations; duplicate spot urine samples have been suggested as a potential better marker to assess the variability of I using statistical modelling to reduce within-individual variation and is better suited for comparison with thresholds ${ }^{(5,50)}$. Diurnal variation in UI concentrations have been reported, with lower concentrations noted in morning samples ${ }^{(51)}$. Therefore, it is important to recognise that, owing to a diurnal effect, the present study's UI concentrations may be higher.

In conclusion, this is the first study presenting nationally representative data for both estimated dietary I intakes and UI concentration for adults resident in Ireland. It shows that I intake and UI concentrations in the majority of adults are sufficient, with milk providing the major contribution to dietary I intake. The lowest intakes and statuses were observed for women of child-bearing age, for whom the possibility of risk of marginal deficiency exists. Data on I intake and status of pregnant women and children should be collected to investigate I adequacy in these important subgroups of the population. Our analysis also identifies I as a unique nutrient, whereby dietary intakes are directly influenced by seasonal changes in agricultural practices. Hence, any change in animal husbandry (e.g. lowering animal feed maximum residue level) could potentially have serious effects on population I status and should be carefully considered, as milk has been found to be the single most important dietary contributor.

\section{Acknowledgements}

None.

This study was funded by the Irish Department of Agriculture, Food and the Marine and the Health Research Board under their joint Food for Health Research Initiative (2007-2012), grant no. 7FHRIUCC2. The Irish Department of Agriculture, Food and the Marine and the Health Research Board had no role in the design, analysis or writing of this article.

The authors' contributions were as follows: M. J. G. and A. F. were involved in conception of the study and are grant holders. C. T., A. P. N., A. F., J. W. and M. J. G. contributed to the design and implementation of the study and preparation of the manuscript. B. A. M. undertook the data analysis and manuscript preparations. All authors reviewed and approved the final manuscript.

The authors declare that there are no conflicts of interest.

\section{Supplementary material}

For supplementary material/s referred to in this article, please visit https://doi.org/10.1017/S0007114516004347

\section{References}

1. World Health Organization, United Nations Children's Fund \& International Health Council for the Control of Iodine Deficiency Disorders (2007) Assessment of Iodine Deficiency Disorders and Monitoring Their Elimination: A Guide for Programme Managers, 32nd ed. Geneva: WHO.

2. de Benoist B, Andersson M, Egli I, et al., eds (2004) Iodine Status Worldwide. WHO Global Database on Iodine Deficiency. Geneva: WHO.

3. Zimmerman MB (2009) Iodine deficiency. Endocr Rec 30, 376-408.

4. Andersson M, de Benoist B, Darnton-Hill I, et al. (2007) Iodine Deficiency in Europe: A Continuing Public Health Problem. Geneva: WHO Press.

5. Zimmermann MB \& Andersson M (2012) Assessment of iodine nutrition in populations: past, present, and future. Nutr Rev 70, 553-570.

6. Andersson M, Karumbunathan V \& Zimmermann MB (2012) Global iodine status in 2011 and trends over the past decade. J Nutr 142, 744-750.

7. Vanderpump MPJ, Lazarus JH, Smyth PP, et al. (2011) Iodine status of UK schoolgirls: a cross-sectional survey. Lancet $\mathbf{3 7 7}$, 2007-2012.

8. Bath SC, Steer CD, Golding J, et al. (2013) Effect of inadequate iodine status in UK pregnant women on cognitive outcomes in their children: results from the Avon Longitudinal Study of Parents and Children (ALSPAC). Lancet 382, 331-337. 
9. Hynes KL, Otahal P, Hay J, et al. (2013) Mild iodine deficiency during pregnancy is associated with reduced educational outcomes in the offspring: 9-year follow-up of the gestational iodine cohort. I Clin Endocrinal Metab 98, 1954-1962.

10. Zimmermann MB, Gizak M, Abbott K, et al. (2015) Iodine deficiency in pregnant women in Europe. Lancet Diabetes Endocrinol 9, 672-674.

11. Nawoor Z, Burns R, Smith DF, et al. (2006) Iodine intake in pregnancy in Ireland - a cause for concern? Ir J Med Sci $\mathbf{1 7 5}$, 21-24.

12. Irish Universities Nutrition Alliance (2011). National Adult Nutrition Survey; Summary Report. Cork: Irish Universities Nutrition Alliance. http://www.iuna.net/?p=106

13. Central Statistics Office (2007) Census 2006: Principal Demographic Results. Dublin: The Stationery Office.

14. Holland B, Unwin ID \& Buss DH (1988) Cereal and Cereal Products. Third Supplement to McCance and Widdowson's The Composition of Foods, 4th ed. London: HMSO.

15. Holland B, Unwin ID \& Buss DH (1989) Milk Products and Eggs. Fourth Supplement to McCance and Widdowson's The Composition of Foods, 4th ed. London: HMSO.

16. Holland B, Unwin ID \& Buss DH (1991) Vegetables, Herbs and Spices. Fifth Supplement to McCance and Widdowson's The Composition of Foods, 4th ed. London: HMSO.

17. Holland B, Unwin ID \& Buss DH (1992) Fruits and Nuts. First Supplement to McCance and Widdowson's The Composition of Foods, 5th ed. London: HMSO.

18. Holland B, Brown J \& Buss DH (1993) Fish and Fish Products. Third Supplement to McCance and Widdowson's The Composition of Foods, 5th ed. London: HMSO.

19. Chan W, Buss DH \& Brown J (1994) Miscellaneous Foods. Fourth Supplement of McCance and Widdowson's the Composition of Foods, 5 th ed. London: HMSO.

20. Chan W, Brown J, Lee SJ, et al. (1995) Meat Poultry and Game. Fifth Supplement of McCance and Widdowson's The Composition of Foods, 5th ed. London: HMSO.

21. Holland B, Welch AA, Unwin ID, et al. (1995) McCance \& Widdowson's The Composition of Foods, 5th ed. Royal Society of Chemistry and Ministry of Agriculture, Fisheries and Food. London: HMSO.

22. Chan W, Brown J, Church SM, et al. (1996) Meat Products and Dishes. Sixth Supplement of McCance and Widdowson's The Composition of Foods, 5th ed. London: HMSO.

23. Holland B, Welch AA \& Buss DH (1996) Vegetable Dishes. Second Supplement to McCance and Widdowson's The Composition of Foods, 5th ed. London: HMSO.

24. Food Standards Agency (2002) McCance and Widdowson's The Composition of Foods, 6th summary edition. Cambridge: Royal Society of Chemistry.

25. Food Saftey Authority of Ireland (2016) Report on a Total Diet Study Carried Out by the Food Safety Authority of Ireland in the Period 2012-2014, Monitoring \& Surveillance Series. Dublin: Food Saftey Authority of Ireland.

26. UK Food Standards Agency (2008) Composition of Foods Integrated Data set (CoFIDS),, www.gov.uk/government/ publications/composition-of-foods-integrated-dataset-cofid (accessed June 2016).

27. National Institute for Health and Welfare (2005) Fineli-Finnish food composition database, release 5. http://www.fineli.fi/ (accessed June 2016).

28. Food Standards Australia New Zealand (2010) Nutrient tables for use in Australia. http://www.foodstandards.gov.au/ science/monitoringnutrients/nutrientables/Pages/default.aspx (accessed June 2016).
29. Ohashi T, Yamaki M, Pandav CS, et al. (2000) Simple microplate method for determination of urinary iodine. Clin Chem $\mathbf{4 6}$, 529-536.

30. Department of Health (1991) Dietary Reference Values for Food, Energy and Nutrients in the United Kingdom, no. 41. London: HMSO.

31. European Food Safety Authority (2014) Scientific Opinion on Dietary Reference Values for iodine. EFSA Panel on Dietetic Products, Nutrition and Allergies (NDA). EFSA J 12, 3660.

32. Institute of Medicine (2001) Dietary Reference Intakes for Vitamin A, Vitamin K, Arsenic, Boron, Chromium, Copper, Iodine, Iron, Manganese, Molybdenum, Nickel, Silicon, Vanadium, and Zinc. Washington: National Academies Press.

33. European Commission, Scientific Committee on Food (2002) Opinion of the Scientific Committee on food on the tolerable upper intake level of iodine. European Commission, SCF/CS/ NUT/UPPLEV/26 final report, Brussels.

34. Black AE (2000) Critical evaluation of energy intake using the Goldberg cut-off for energy intake: basal metabolic. A practical guide to its calculation, use and limitations. Int J Obes Relat Metab Disord 24, 1119-1130.

35. World Health Organization, United Nations Children's Fund \& International Health Council for the Control of Iodine Deficiency Disorders (2001) Assessment of Iodine Deficiency Disorders and Monitoring their Elimination (WHO/NHD/ 01.1). Geneva: WHO .

36. Ramussen LB, Ovesen L, Bülow I, et al. (2002) Dietary iodine intake and urinary iodine excretion in a Danish population: effect of geography, supplements and food choice. Br J Nutr 87, 61-69.

37. Whitton C, Nicholson SK, Roberts C, et al. (2011) National Diet and Nutrition Survey: UK food consumption and nutrient intakes from the first year of the rolling programme and comparisons with previous surveys. Br J Nutr 106, 1899-1914.

38. Scientific Advisory Committee on Nutrition (2014) [2006] Statement on Iodine and Health. London: The Stationery Office.

39. Murray CW, Egan SK, Kim H, et al. (2008) US Food and Drug Administration's Total Diet Study: dietary intake of perchlorate and iodine. J Expo Sci Environ Epidemiol 18, 571-580.

40. Maalouf J, Barron J, Gunn JP, et al. (2015) Iodized salt sales in the United States. Nutrients 7, 1691-1695.

41. Johner SA, Thamm M, Nöthlings U, et al. (2013) Iodine status in preschool children and evaluation of major dietary iodine sources: a German experience. Eur J Nutr 52, 1711-1719.

42. Smyth PP, Hetherton AM, Smith DF, et al. (1997) Maternal iodine status and thyroid volume during pregnancy: correlation with neonatal iodine intake. J Clin Endocrinol Metab 82, 2840-2843.

43. Bath SC \& Rayman MP (2015) A review of the iodine status of UK pregnant women and its implications for the offspring. Environ Geochem Health 37, 619-629.

44. Phillips DI (1997) Iodine, milk, and the elimination of endemic goitre in Britain: the story of an accidental public health triumph. J Epidemiol Community Health 51, 391-393.

45. Bath SC, Hill S, Goenaga-Infante H, et al. (2016) Iodine concentration of milk-alternative available in the UK. Proc Nutr Soc; OC 51 (In the Press).

46. European Food Safety Authority (2013) Scientific opinion on the safety and efficacy of iodine compounds (E2) as feed additives for all species: calcium iodate anhydrous and potassium iodide, based on a dossier submitted by HELM AG. EFSA J 11, 3101-3125.

47. World Health Organization (2014) Guideline: Fortification of Food-Grade Salt with Iodine for the Prevention and Control of Iodine Deficiency Disorders. Geneva: WHO. 
48. Edmonds J \& Ryan T (2012) Dietary Iodine Intake of New Zealand Children Following Fortification of Bread with Iodine. Wellington: Ministry of Agriculture and Forestry.

49. European Commission (2011) Regulation (EU) No. 1369/2011 of the European Parliament and of the Council of 25 October 2011 on the provision of food information to consumers. Official Journal of the European Communities L304, 18-63.
50. Rohner F, Zimmermann M, Jooste $\mathrm{P}$, et al. (2014) Biomarkers of nutrition for development - iodine review. J Nutr $\mathbf{1 4 4}$, 1322S-1342S.

51. Als C, Helbling A, Peter K, et al. (2000) Urinary iodine concentration follows a circadian rhythm: a study with 3023 spot urine samples in adults and children. J Clin Endocrinol Metab 85, 1367-1369. 